\title{
LETTERS
}

\section{Duloxetine: urinary incontinence and marketing authorization incontinence}

Maund and colleagues ${ }^{1}$ rightly questioned the use of duloxetine for stress urinary incontinence, with a focus on harms related to suicidality and violent behaviour, but the problem is deeper.

First, duloxetine has no advantages versus other antidepressants, but has only specific serious adverse effects, such as lifethreatening liver injury ${ }^{2}$ and severe skin reactions, including Stevens-Johnson syndrome. ${ }^{3}$ Duloxetine is in a yearly list of "drugs to avoid" - drugs on the market that are more harmful than beneficial. ${ }^{4}$ This Choosing Wisely initiative remains deliberately ignored by regulatory agencies.

Second, patients with stress incontinence are usually older, and as a result coexistence of other somatic diseases is very frequent with polymedication. This is a major drug safety issue.

Last, how could the European Medicine Agency have granted a marketing authorization for stress urinary incontinence without either long-term assessment of the safety or adequate assessment of efficacy versus a comparator? Indeed, other options, with a stepped-care approach that advances from least invasive to more invasive interventions, are available (e.g., behavioural modification, pelvic floor muscle exercises, noninvasive stimulation, vaginal inserts, urethral plugs, neuromod- ulation devices, injections of periurethral bulking agents, and sling and urethropexy procedures). ${ }^{5}$ No medications are approved by the United States Food and Drug Administration for this condition. Why this European exception? Exceptions rarely benefit patients.

Why do some practitioners prescribe duloxetine, whatever the indication, and ignore safer alternatives?

\section{Alain Braillon MD PhD}

Senior consultant, University Hospital, Amiens, France

Cite as: CMAJ 2017 March 6;189:E373. doi: $10.1503 / \mathrm{cmaj} .732561$

\section{References}

1. Maund E, Guski LS, Gøtzsche PC. Considering benefits and harms of duloxetine for treatment of stress urinary incontinence: a meta-analysis of clinical study reports. CMAJ 2017;189: E194-203.

2. Wernicke J, Pangallo B, Wang F, et al. Hepatic effects of duloxetine-I: non-clinical and clinical trial data [published erratum in Curr Drug Saf 2009;4:94]. Curr Drug Saf 2008;3:132-42.

3. Cymbalta (duloxetine hydrochloride). Silver Spring (MD): US Food and Drug Administration; 2011. Available: www.fda.gov/Safety/MedWatch/ Safetylnformation/ucm255064.htm (accessed 2017 Jan. 27)

4. Towards better patient care: drugs to avoid in 2016 [article in French]. Prescrire Int 2016;25: 105-11.

5. Hersh L, Salzman B. Clinical management of urinary incontinence in women [published erratum in Am Fam Physician 2013;88:427]. Am Fam Physician 2013;87:634-40.

Competing interests: None declared. 